\title{
Trends in Basic Mathematical Competencies of Beginning Undergraduates in Ireland, 2003-2013
}

\author{
Fiona Faulkner \\ Technological University Dublin, fiona.faulkner@tudublin.ie \\ Paraic Treacy \\ University of Limerick
}

Follow this and additional works at: https://arrow.tudublin.ie/ltcart

Part of the Education Commons

\section{Recommended Citation}

Faulkner, F. \& Treacy, P. Trends in basic mathematical competencies of beginning undergraduates in Ireland, 2003-2013. International Journal of Mathematical Education in Science and Technology, vol. 46, no. 8, pp. 1182-1196. doi.org/10.1080/0020739X.2015.1050707

This Article is brought to you for free and open access by the Learning Teaching \& Assessment at ARROW@TU Dublin. It has been accepted for inclusion in Articles by an authorized administrator of ARROW@TU Dublin. For more information, please contact arrow.admin@tudublin.ie, aisling.coyne@tudublin.ie, gerard.connolly@tudublin.ie.

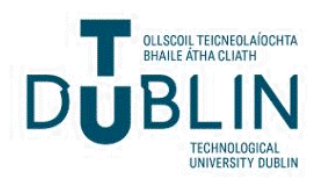




\title{
Trends in basic mathematical competencies of beginning undergraduates in Ireland, 2003-2013
}

\author{
Páraic Treacy ${ }^{\mathrm{a} *}$ and Fiona Faulkner ${ }^{\mathrm{b}}$ \\ ${ }^{a}$ Department of Mathematics and Statistics, University of Limerick, Limerick, Ireland; ${ }^{b}$ Hospitality \\ Management and Tourism Department, Dublin Institute of Technology, Dublin, Ireland
}

(Received 18 November 2014)

\begin{abstract}
Deficiencies in beginning undergraduate students' basic mathematical skills has been an issue of concern in higher education, particularly in the past 15 years. This issue has been tracked and analysed in a number of universities in Ireland and internationally through student scores recorded in mathematics diagnostic tests. Students beginning their science-based and technology-based undergraduate courses in the University of Limerick have had their basic mathematics skills tested without any prior warning through a 40 question diagnostic test during their initial service mathematics lecture since 1998. Data gathered through this diagnostic test have been recorded in a database kept at the university and explored to track trends in mathematical competency of these beginning undergraduates. This paper details findings surrounding an analysis of the database between 2003 and 2013, outlining changes in mathematical competencies of these beginning undergraduates in an attempt to determine reasons for such changes. The analysis found that the proportion of students tested through this diagnostic test that are predicted to be at risk of failing their service mathematics end-of-semester examinations has increased significantly between 2003 and 2013. Furthermore, when students' performance in secondary level mathematics was controlled, it was determined that the performance of beginning undergraduates in 2013 was statistically significantly below that of the performance of the beginning undergraduates recorded 10 years previously.
\end{abstract}

Keywords: mathematical competencies; basic mathematical skills; under-preparedness; mathematics education

\section{Introduction}

The mathematical under-preparedness of students entering universities in Ireland, UK, Australia, and the United States has been widely reported with beginning undergraduates displaying a lack of basic mathematical skills, as well as fragmented understanding, inadequate concept knowledge, and inability to successfully solve mathematical problems.[1-5] This phenomenon in which students are under prepared for the mathematical demands of their undergraduate courses is regularly referred to as the 'Maths Problem'.[6]

The declining standards of beginning undergraduates' basic mathematical skills coupled with the recent findings that over four-fifths of school leavers in Ireland reported significant differences in approaches to teaching and learning between secondary level and further/higher education, highlight the challenges encountered by students when commencing their tertiary studies.[7] As such, it is no surprise that difficulties encountered due to

\footnotetext{
${ }^{*}$ Corresponding author. Email: paraic.treacy@ul.ie
} 
student deficiencies in mathematics was determined to be a key contributing factor to low retention rates in higher education STEM (Science, Technology, Engineering, Mathematics) courses.[8]

In the UK, the 'Maths Problem' has become a matter of such significance that Vorderman et al. [9, p.7] recommended that mathematics should be given special status as a 'subject of critical importance', due in part to their findings that the mathematical skills of typical British 15-year olds are as much as two years behind those of their international counterparts. It has also been estimated that, in any given year, 330,000 of those entering universities in the UK would benefit from having studied mathematics and statistics beyond the GCSE (General Certificate in Secondary Education) level, however typically less than 125,000 have done so.[10] A report commissioned by the Royal Society for the encouragement of Arts, Manufactures and Commerce (RSA) in 2012 also noted the poor levels of mathematical competencies of university entrants in the UK, indicating that substandard performance at GCSE level and low levels of participation after the age of 16 are significant factors affecting this issue.[11] The situation in the United States is similar with reports in August 2014 indicating that only 43\% of students who took the American College Testing (ACT) mathematics examination - a standardized test for high school achievement and college admissions - were considered to be mathematically 'college ready'.[12]

In Ireland, measures have recently been put in place in an attempt to counteract the deficiencies reported in students' mathematical performances within secondary level education. Significant changes have been made to the secondary school mathematics curricula at both junior cycle (years 1-3 of secondary level) and senior cycle (years 5-6 of secondary level) with the introduction of the 'Project Maths' syllabi. These new syllabi aim to place greater emphasis on student understanding of mathematical concepts, enabling students to relate mathematics to everyday scenarios with increased use of contexts and applications. Project Maths also aims to promote further focus on problem-solving skills and the alignment of assessment with the aforementioned revised classroom practices.[13]

Further to the introduction of new mathematics curricula, action has been taken to ensure that mathematics teachers at secondary level are sufficiently qualified to teach the subject. In a 2009 study, $48 \%$ of teachers in Ireland assigned to teach secondary level mathematics were found to be 'out-of-field', i.e. teaching a subject which does not match their training or education.[14] In an attempt to upskill teachers who do not have a formal qualification in mathematics teaching, the Professional Diploma in Mathematics for Teaching (parttime) was introduced. This 2-year part-time blended learning programme, which is free of charge to successful applicants, was rolled out nationwide in 2012, with the first cohort of approximately 300 teachers graduating in January 2015.

This focus on improving mathematics education at secondary level to prepare students adequately for tertiary level education is understandable as it has been determined that mathematics is the strongest predictor of successful student progression through tertiary level education in Ireland.[15] Similarly, one of the key motivating factors for the focus on improvement in mathematics performance is the important role it plays in a country's economic success as developed nations focus on achieving a knowledge society through greater rates of higher education within its population.[16] However, as this paper will discuss in detail, Irish tertiary level institutions, such as the University of Limerick (UL), are now encountering university entrants to science- and technology-based courses with significantly inferior basic mathematical skills when compared to those encountered as recently as 10 years ago.

The concentration of effort and investment put forth in Ireland to improve mathematics education at secondary level in recent years only adds to the importance of the findings outlined in this paper surrounding beginning undergraduate students' mathematics 
competencies between 2003 and 2013. The means by which these students' performance of basic mathematical skills were determined will be outlined along with a general profile of the students' mathematical backgrounds. Futhermore, a detailed analysis of the trends related to student performance on the UL mathematics diagnostic test will be outlined.

\section{Mathematical background of Irish students}

The vast majority of students who leave secondary level education to enter tertiary level education in Ireland have studied mathematics for the duration of their academic lives. Mathematics is one of three subjects that students must complete in their final examinations at secondary level - the leaving certificate examinations. Once secondary school students complete senior cycle in Ireland, typically at age 17 or 18 , they sit the leaving certificate mathematics examination at one of three levels - higher, ordinary, or foundation. The aforementioned Project Maths syllabus was phased in to the senior cycle in all Irish secondary schools, starting in September 2010 and eventually fully rolled out by September 2013. Elements of the Project Maths syllabus were thus incorporated into the leaving certificate mathematics examinations in June 2011, with gradually more added in June 2012, June 2013, and June 2014. The first examination to be completely based on the new syllabus in all Irish secondary schools will take place in June 2015. An early assessment of the impact of Project Maths was published in November 2013 in which it was determined that the new syllabi, at both junior cycle and senior cycle, do not appear to be linked with any overall decline or progression in students' achievement in mathematics.[17]

Results in the leaving certificate examinations determine whether or not a student transitions directly from secondary level education to tertiary level education in Ireland. Points are awarded based on the grades achieved in the Leaving Certificate examinations (see Table 1). The number of points achieved by a student determines the tertiary level courses to which he/she may gain entry. Beginning in 2012, 25 bonus points were awarded to students who achieved a grade D3 or above in the higher level leaving certificate mathematics examination.

\section{The diagnostic test and methodology}

Since 1998, students entering first year service mathematics modules at UL - Science Mathematics 1 and Technological Mathematics 1 - have been given a 40 question diagnostic test, which assesses basic skills and understanding in various mathematical topics. These topics

Table 1. Points awarded for grades achieved in leaving certificate examinations.

\begin{tabular}{lrcr}
\hline Grade & Points & Grade & Points \\
\hline HA1 & 100 & OA1 & 60 \\
HA2 & 90 & OA2 & 50 \\
HB1 & 85 & OB1 & 45 \\
HB2 & OB2 & 40 \\
HB3 & 80 & OB3 & 35 \\
HC1 & 75 & OC1 & 30 \\
HC2 & 70 & OC2 & 25 \\
HC3 & 65 & OC3 & 20 \\
HD1 & 60 & OD1 & 15 \\
HD2 & 55 & OD2 & 10 \\
HD3 & 50 & OD3 & 5 \\
\hline
\end{tabular}

Note: HA1 represents an A1 grade at higher level; OB3 represents a B3 grade at ordinary level. 
include arithmetic (13 questions), algebra (8 questions), geometry (4 questions), trigonometry (3 questions), co-ordinate geometry (4 questions), complex numbers (2 questions), differentiation (3 questions), integration (2 questions), and modelling (1 question).

Thirty four of these questions are set at a leaving certificate ordinary level standard or below, with the other six questions set at a leaving certificate higher level standard. Students who score $18 / 40$ or less are considered to be at risk of failing their service mathematics module thus they are deemed to be 'at risk'. This mark had been initially set at 19/40 but work by Faulkner [5] objectively proved that setting this mark at 18/40 was a more accurate prediction of students' likely performance based on retrospective data. Students who are considered 'at risk' are advised to use mathematics support services at the university early and often during the semester in an attempt to address any gaps in their basic mathematical knowledge.

The UL diagnostic test was designed specifically to suit the mathematical level of the students in each of the targeted service mathematics modules. Within this design process, a team of experienced service mathematics lecturers analysed and adjusted an initial list of 70 questions, reducing this to the final 40 question version. To ensure the validity of this test, it was then piloted in Irish secondary schools and compared with the European Society for Engineering Education (SEFI) Core Level Zero syllabus for engineers, the Irish Junior Certificate mathematics syllabus, the Irish Leaving Certificate mathematics syllabus, and further diagnostic tests.[2]

Data on the cohort of Science Mathematics 1 and Technological Mathematics 1 students who sat this diagnostic test each year between 1998 and 2013 have been collected with the same diagnostic test used each time to ensure reliability. The UL database, which contains data from these diagnostic tests, currently holds information on over 10,100 students. This paper will focus on data from 2003 to 2013 so that clear trends can be observed and analysed over a recent extended period.

Analysis of this data was carried out in an attempt to aid the authors in answering the following research questions:

- What are the basic mathematical skills of beginning undergraduates in UL service mathematics modules?

- What proportion of students entering UL service mathematics modules are categorised 'at risk' in the years between and including 2003 and 2013 ?

- What are the trends in performance of basic mathematical skills of students entering first-year service mathematics modules at UL?

- Is there any evidence of grade dilution in leaving certificate mathematics in the period 2003-2013?

\section{Profiling beginning undergraduates' mathematical backgrounds}

Prior to discussing the diagnostic test performances of students entering service mathematics modules at UL, consideration must be given to the mathematical backgrounds of these students. As can be observed in Figure 1, the majority of students who sat the diagnostic test each year studied ordinary level mathematics at leaving certificate level (between 50\% and $60.8 \%$ ). The gap between proportions of students studying ordinary level and higher level at leaving certificate was least pronounced in 2004 and 2013, with the widest gap forming in 2010 (see Figure 1).

It is clear from the data (see Figure 1) that the proportion of students entering the Science Mathematics 1 and Technological Mathematics 1 modules at UL that have studied 


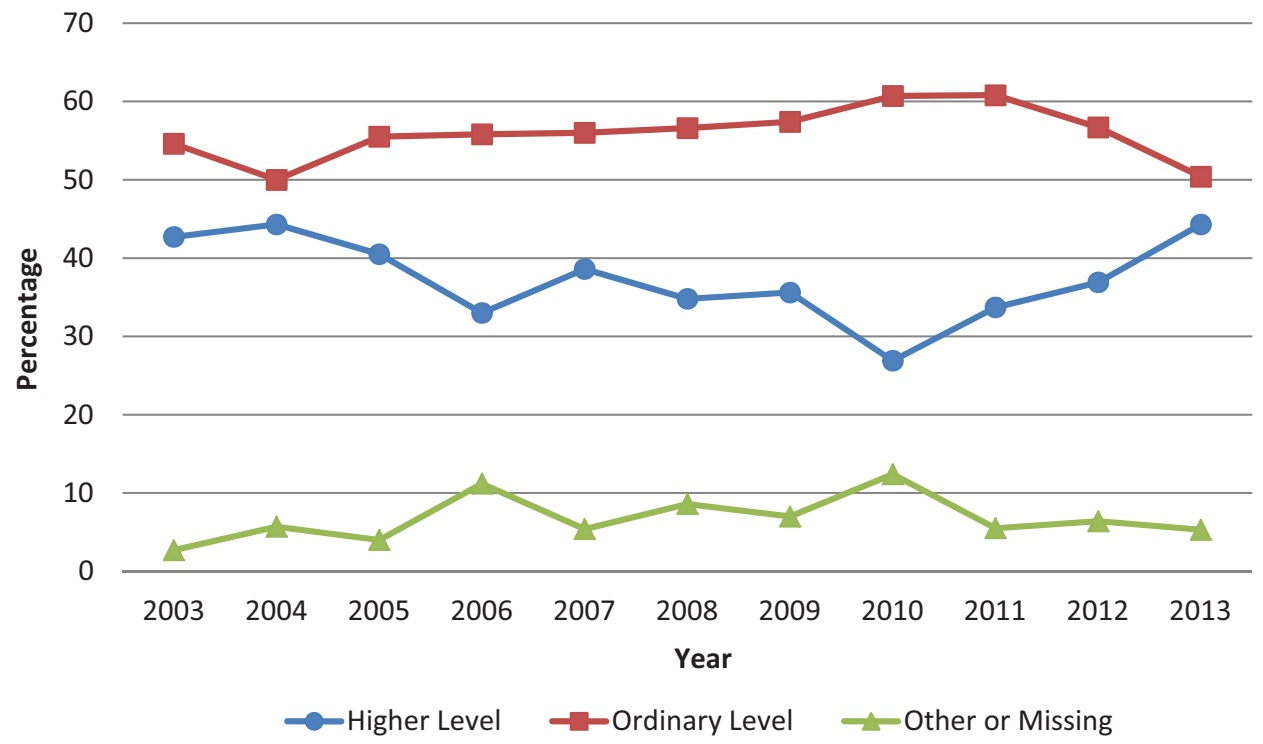

Figure 1. Proportion of students entering UL service mathematics modules from leaving certificate higher level, leaving certificate ordinary level or other (2003-2013).

leaving certificate mathematics at higher level has increased steadily since 2010 . This may be partly explained by the offer of 25 extra points in the leaving certificate for those who achieve a D3 grade or greater in the higher level mathematics examination. This initiative, as indicated previously, was introduced in 2012 and was continued in 2013 and 2014. The introduction of these bonus points has coincided with a marked rise in the proportion of students opting for higher level mathematics at leaving certificate in Ireland, rising from $16 \%$ in 2011 to $22 \%$ in $2012,25.6 \%$ in 2013 , and $27 \%$ in 2014 .[18]

Students were termed as 'Other/Missing' in the database if they completed their secondary level studies outside Ireland, did not sit their leaving certificate in the previous 10 years, or did not sit a leaving certificate mathematics examination at all. As is evident in Figure 1, these students typically accounted for a small percentage of each cohort, i.e. between $2.4 \%$ and $12.4 \%$, with no pattern of note to this variation.

The overall secondary level mathematical performance of students entering these service mathematics modules each year cannot be accurately determined by the proportion of students who entered from a background of higher level or ordinary level leaving certificate studies. Thus, a graphical comparison of the grades achieved by these students each year (see Figure 2) will be used as a means for comparison of mathematical performance in the leaving certificate examination between 2003 and 2013. Analysis of this data (see Figure 2) indicates that students have achieved similar grades in leaving certificate examinations in the timeframe explored (2003-2013). There are, however, some differences in the years 2012 and 2013 when compared to the years previous as the proportion of students achieving ordinary level A grades (OA) declined while the proportion of those achieving higher level $\mathrm{C}$ grades (HC) and higher level D grades (HD) increased. This change could be explained by the introduction of bonus points during that period - those that typically would have been expected to achieve ordinary level A grades in 2012 and 2013 may have decided to study higher level leaving certificate mathematics to attempt to take advantage of the bonus points on offer. 


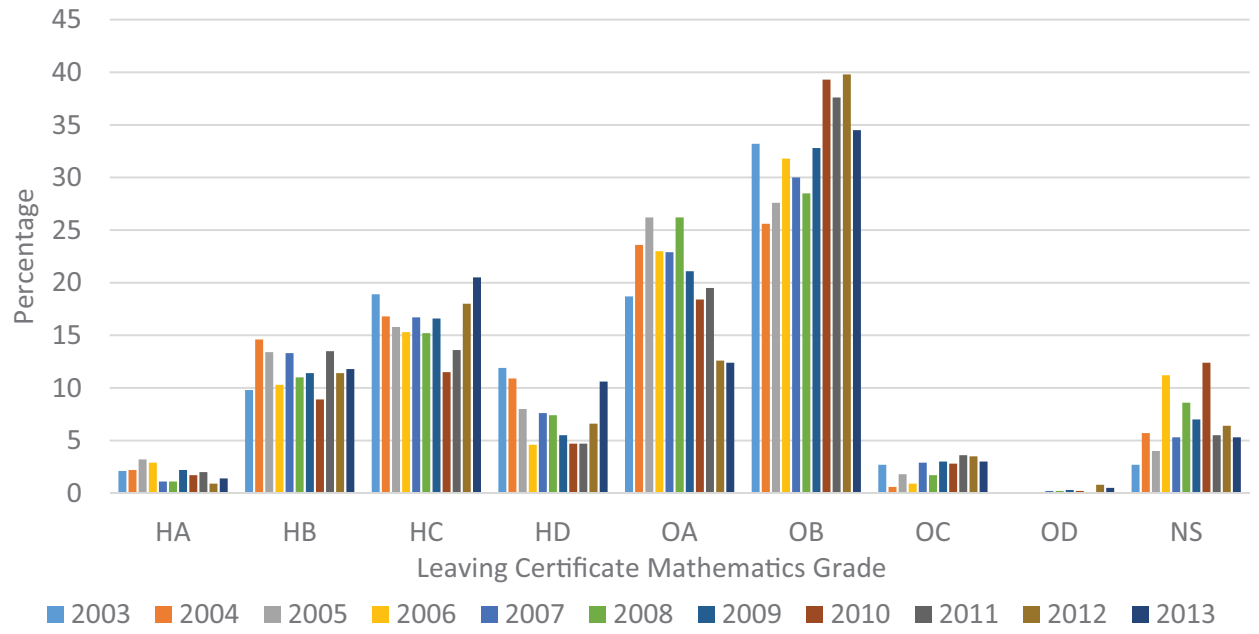

Figure 2. Percentage of students entering UL service mathematics modules that achieved specific leaving certificate mathematics grades (2003-2013).

Overall, this data indicates that a similar proportion of students achieved matching leaving certificate mathematics grades between 2003 and 2013. The proportion of 'Other or Missing' students, i.e. their grade is not stated, has only fluctuated slightly between 2003 and 2013, thus it is unlikely to have a significant impact on the overall performance of each cohort. Taking into account these findings, one would expect that students from each cohort analysed between 2003 and 2013 would perform the basic mathematical skills tested through the previously outlined diagnostic test at similar levels. This expectation was largely due to the conclusion drawn by Faulkner et al. [19] that students entering UL with particular leaving certificate mathematics grades performed to a similar level in the diagnostic test between 1998 and 2008. However, such consistency in performance was not present when the data gathered between 2003 and 2013 were analysed. The next section will chart the analysis of the differences observed in student performance through the UL diagnostic test in the years between 2003 and 2013, with a particular focus on the increase in the proportion of students considered to be 'at risk'.

\section{Proportions of 'At Risk' students in service mathematics modules}

As indicated previously, students who scored 18 out of 40 or less on the diagnostic test were deemed to be 'at risk', i.e. at risk of failing their service mathematics module. The percentage of students 'at risk' in both Science Mathematics 1 and Technological Mathematics 1 modules was determined each year between 2003 and 2013. Analysis of the data clearly indicates that there has been a substantial increase in the proportion of each cohort considered to be 'at risk' (see Figure 3). The percentage of 'at risk' students in a given cohort has risen from 30.6\% in 2003 and $25.6 \%$ in 2004 to $53.7 \%$ in 2012 and $48.7 \%$ in 2013 - this represents a statistically significant $(p<0.01) 59.2 \%$ increase in the proportion of 'at risk' students between 2003 and 2013.

Such significant increases in students predicted to be at risk of failing service mathematics modules is an alarming indicator, particularly when considering overall retention rates in tertiary level education. This statistic is of particular concern in an Irish context as 
60

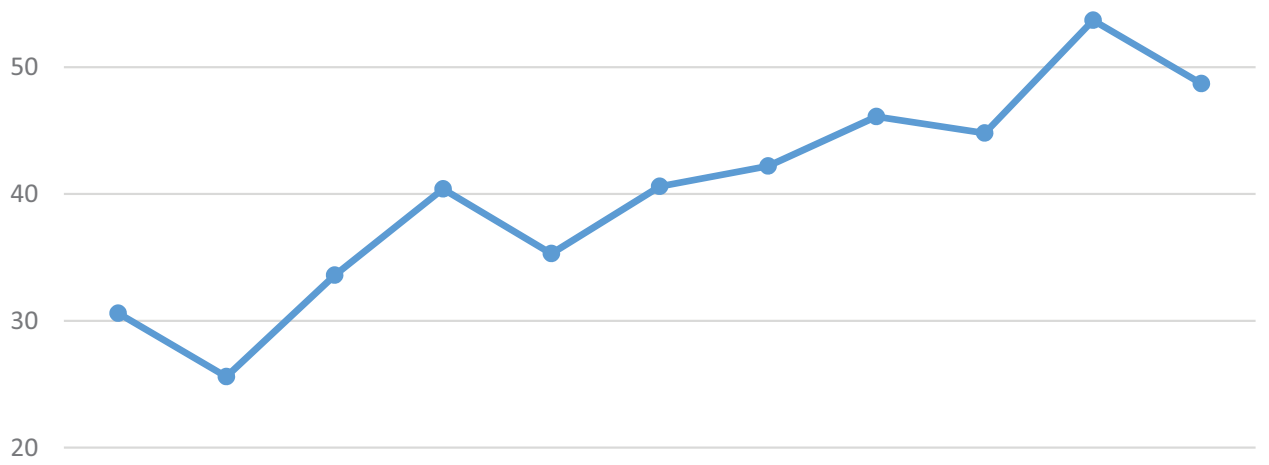

10

0

$\begin{array}{lllllllllll}2003 & 2004 & 2005 & 2006 & 2007 & 2008 & 2009 & 2010 & 2011 & 2012 & 2013\end{array}$

Figure 3. Percentage of yearly cohort that scored $18 / 40$ or less in the UL diagnostic test.

it has been demonstrated that mathematics is the strongest predictor of successful student progression through tertiary level in Ireland.[15]

The declining standards in basic mathematical skills of beginning undergraduates outlined above need to be considered in greater detail to determine the factors which have influenced this decline. These factors will be determined through a detailed exploration of diagnostic test scores between 2003 and 2013.

\subsection{Trends in diagnostic test performance by leaving certificate mathematics level}

Further insight into the declining mathematical standards of beginning undergraduates as measured by the diagnostic test can be observed when the mean score for all students is considered in terms of the level of mathematics studied by these students at leaving certificate level. It is clear (see Figure 4) that the performance of students in the diagnostic test who have studied mathematics at higher level for the leaving certificate maintained a relatively consistent level between 2003 and 2011 with mean scores, which ranged between 25.86 and 27.45 but registered a marked decline in 2012 and 2013 with mean scores of 23.43 and 23.64, respectively. Thus, the performance level of these students as measured by the diagnostic test has fallen by $12.6 \%$ between 2003 and 2013 which proved to be statistically significant $(p<0.01)$.

A similar trend can also be observed for students who studied ordinary level mathematics for the leaving certificate as their mean diagnostic test performance has fallen from 18.61 in 2003 and 19.5 in 2004 to 15.6 in 2012 and 15.68 in 2013 - this indicates a $15.7 \%$ decrease in performance between 2003 and 2013. Again, this difference proved to be statistically significant $(p<0.01)$. 


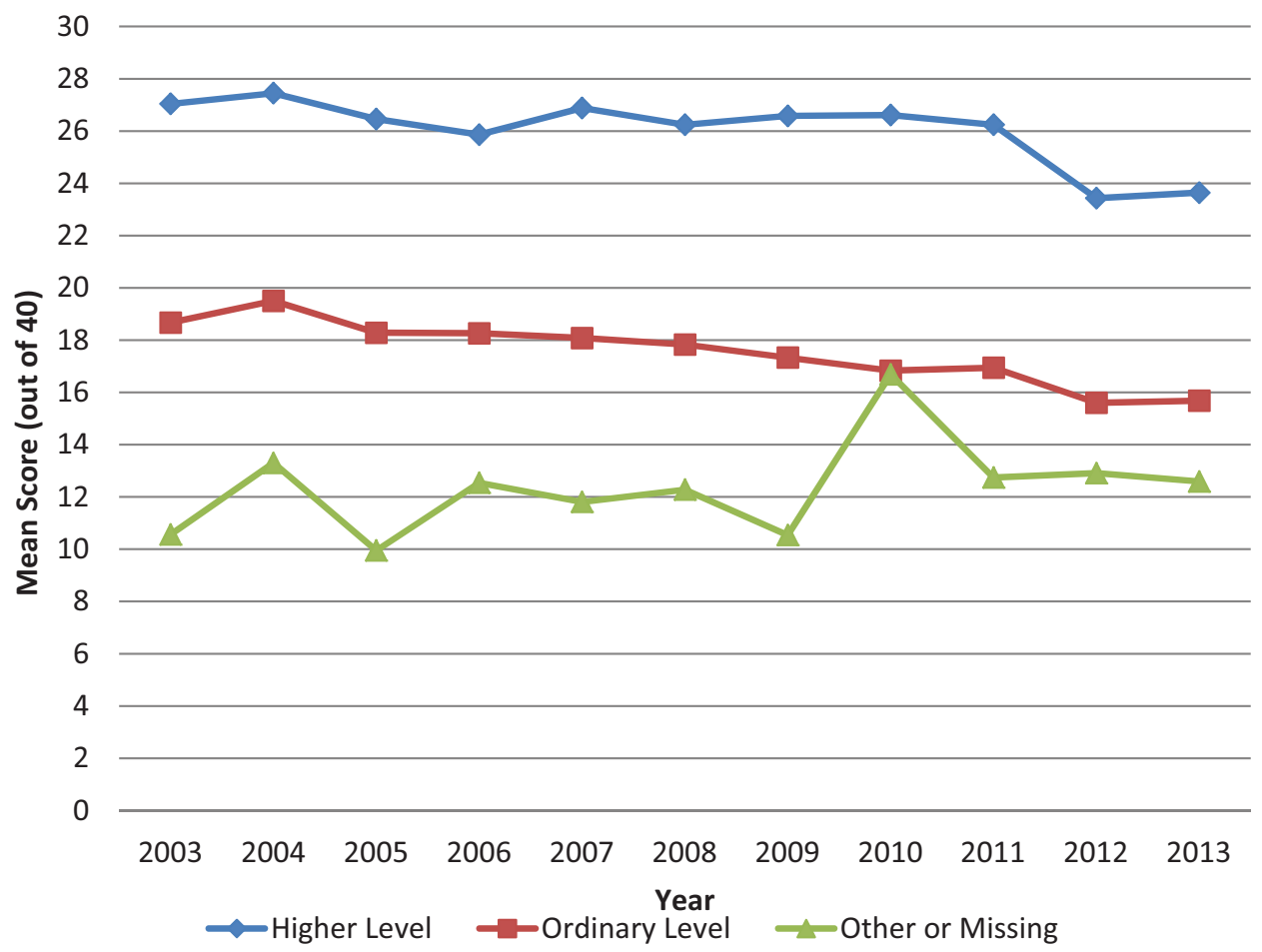

Figure 4. Diagnostic test performance according to leaving certificate mathematics level studied (2003-2013).

From these findings, it could be argued that the basic mathematical skills of beginning undergraduates at the University of Limerick have declined considerably. Evidence for this argument could be observed in the statistically significant increases in 'at risk' students (see Figure 3), as well as the statistically significant decline in performance of those with a higher level leaving certificate background and the statistically significant decline in performance of those with an ordinary level leaving certificate background (see Figure 4). However, consideration must be given to the effect that bonus points have had on the typical profile of students with a background of higher level mathematics and ordinary level mathematics at leaving certificate since 2011 (outlined in section 4). Such a consideration prompts the question: Are the noted trends due to an overall decline in basic mathematical skills of beginning undergraduates or could these trends be explained by the movement from ordinary level to higher level of those who would typically have been high achievers at ordinary level? Such a shift could cause a reduction in the number of high performing students at ordinary level and an increase in the number of low to mediocre performing students at higher level, thus, affecting the mean diagnostic test scores for students with higher level and ordinary level leaving certificate mathematics backgrounds. This consideration prompted the authors to explore the UL database further.

To determine whether there has been a genuine decline in basic mathematical skills of beginning undergraduates at UL when leaving certificate mathematics examination performance is controlled, a more in-depth analysis of the UL database was performed by the authors. The next section will outline this analysis which consisted of comparisons between the cohorts of students who completed the diagnostic test in 2003 and 2013. 


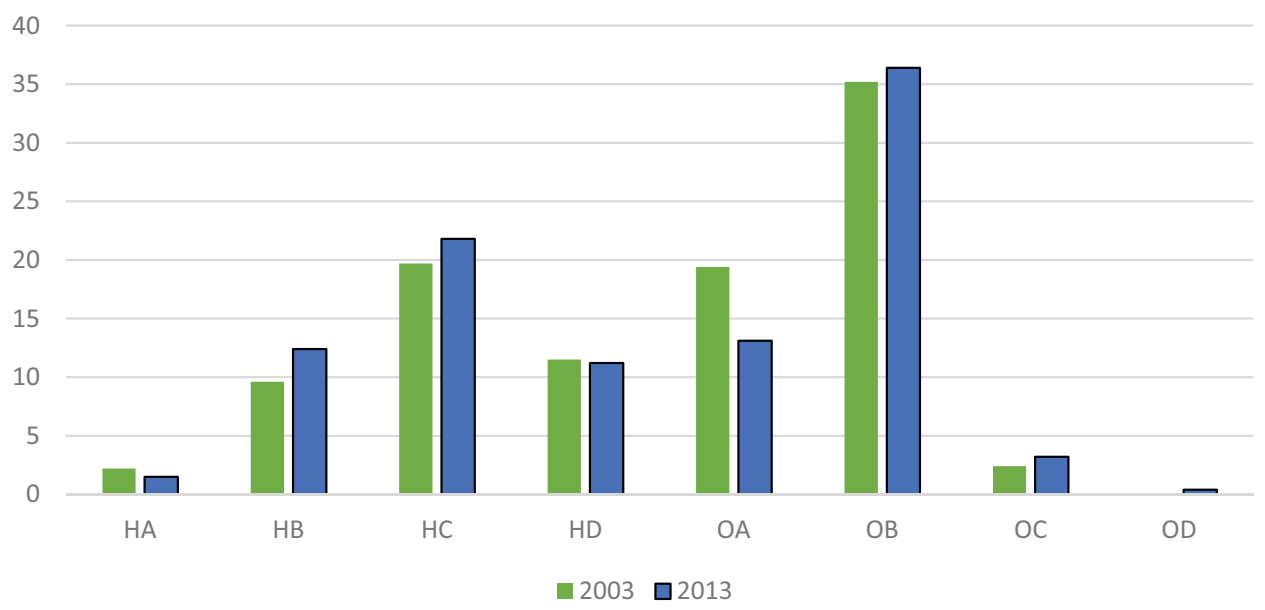

Figure 5. Proportion of leaving certificate grades achieved by students entering UL service mathematics modules in 2003 and 2013.

\subsection{3 vs. 2013: a comparison}

The analysis detailed in the previous section suggests that the standard of basic mathematical skills of students as measured by the UL diagnostic test upon completion of their leaving certificate may be in decline. However, the reservations stated previously which relate to the possible effects of the introduction of bonus points have prompted further analysis in order to elicit more definitive answers to the previously stated research questions (see Section 3). To this end, the authors have isolated the data gathered in 2003 and 2013 so that a more in-depth analysis may be undertaken to ascertain the reasons for the overall decline in basic mathematical skills of beginning undergraduates. These sets of data were selected due to the observation that achievement in mathematics by students in each of these cohorts at leaving certificate is very similar (see Figure 5). The 2013 group has slightly greater proportions of higher level B grades and higher level $\mathrm{C}$ grades but the 2003 group has a greater proportion of ordinary level A grades. The proportions of students who achieved other grade levels are quite similar when 2003 and 2013 are compared.

However, when performance in the diagnostic test is considered, such similarities between these two cohorts are not present. Performance by higher level students in 2003 produced a mean score of 27.04 in the diagnostic test while higher level students in 2013 achieved a mean of 23.64 (see Table 2 ) - a statistically significant $(p<0.01) 12.6 \%$ decline in performance. Similarly, in 2003, of those who had studied higher level leaving certificate mathematics, only $4.1 \%$ were deemed to be 'at risk', while in $2013,21.3 \%$ of students who had studied higher level leaving certificate mathematics were considered to be 'at risk' this increase also proved to be statistically significant $(p<0.01)$.

A similar trend can be observed when considering the students with an ordinary level leaving certificate mathematics background in both cohorts. The mean score in the diagnostic test among these students fell from 18.61 in 2003 to 15.68 in 2013 - a statistically significant $(p<0.01) 15.7 \%$ decline in performance. Of the 2003 students with an ordinary level leaving certificate mathematics background, $57.8 \%$ were considered 'at risk' while, in 2013, a statistically significant $(p<0.01)$ increase was recorded when $84 \%$ of students with an ordinary level leaving certificate mathematics background were considered to be 'at risk'. 


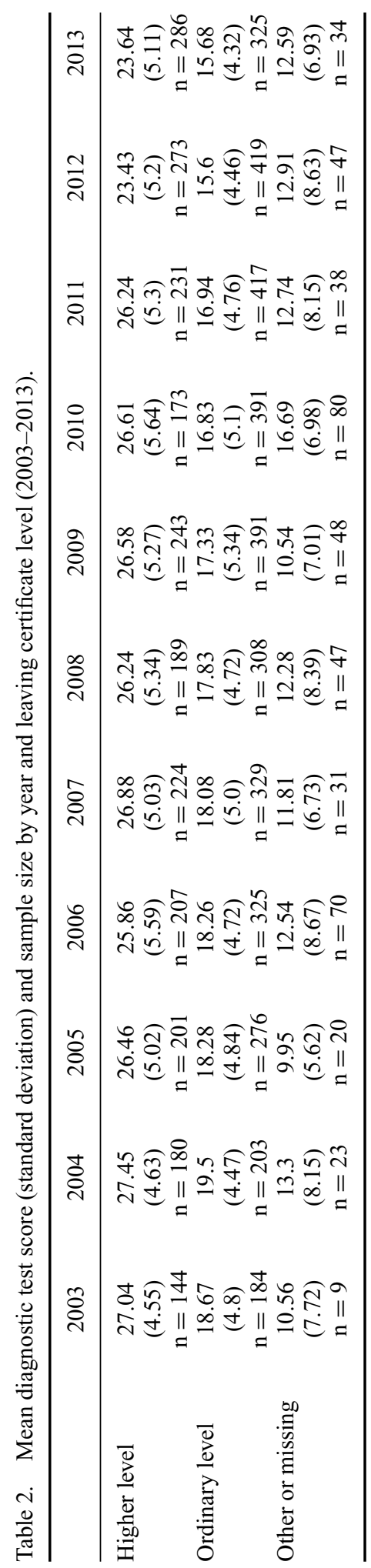




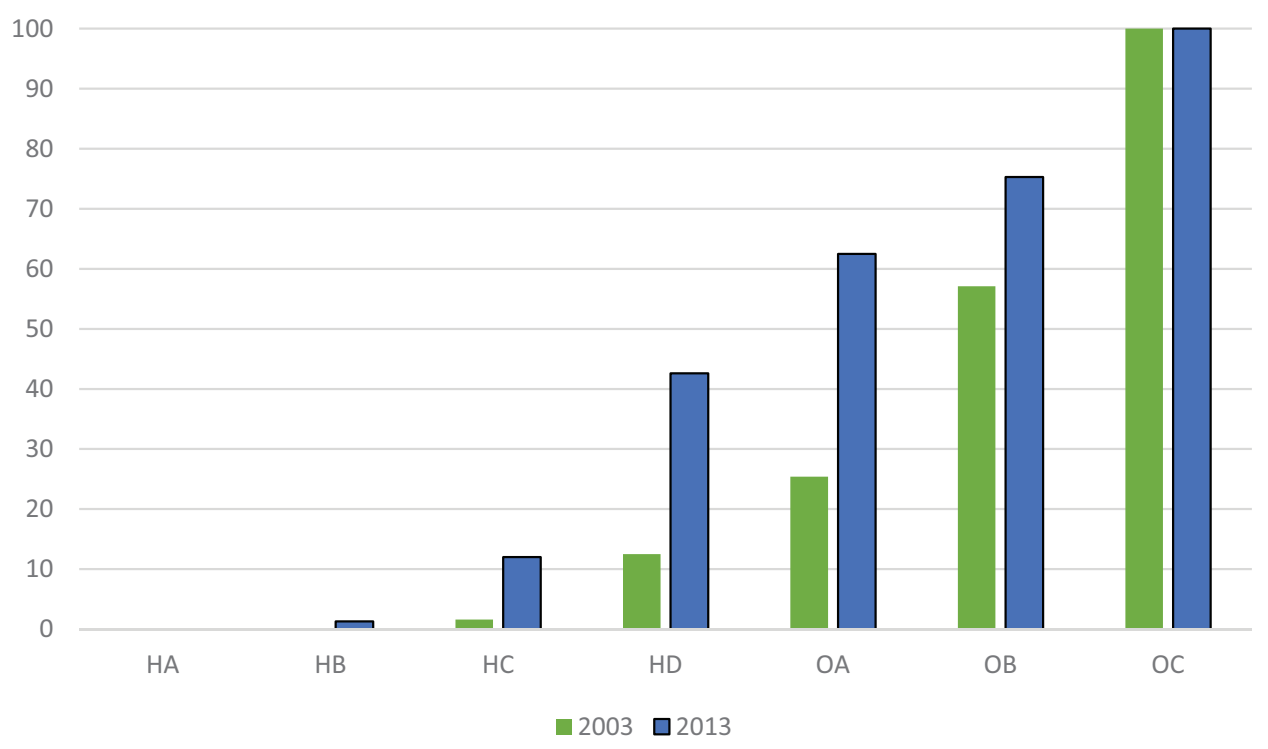

Figure 6. Percentage of students that achieved a given leaving certificate grade who were deemed to be 'at risk' in 2003 and 2013.

If the proportion of students deemed to be 'at risk' is considered for each individual leaving certificate mathematics grade range then the comparison once again highlights the difference in diagnostic test performance between those tested in 2003 and those tested in 2013 (see Figure 6). For example, of those who achieved a higher level grade $\mathrm{C}$ at leaving certificate in 2013, 12\% were considered to be 'at risk' according to the diagnostic test, while in 2003 the corresponding figure was $1.6 \%$. Statistically significant $(p<0.05)$ increases in proportions of 'at risk' students were also recorded at higher level $\mathrm{C}$, higher level $\mathrm{D}$, ordinary level $\mathrm{A}$, and ordinary level $\mathrm{B}$ grade ranges.

It is worth noting also that the proportion of 'at risk' students in 2003 who achieved a higher level grade $\mathrm{C}$ in the leaving certificate is almost identical to the proportion of 'at risk' students in 2013 who achieved a higher level grade B in the leaving certificate. Similarly, the proportion of 'at risk' students in 2003 who achieved a higher level grade D in the leaving certificate is almost identical to the proportion of 'at risk' students in 2013 who achieved a higher level grade $\mathrm{C}$ in the leaving certificate.

These highlighted differences in performance prompt consideration regarding the cause of such declining achievement in the UL diagnostic test. Students entered in the database in 2003 and 2013 had reasonably similar grades in leaving certificate mathematics upon entry to UL, they took the same diagnostic test at the same stage of their initial year in tertiary level education, so why the statistically significant difference in diagnostic test performance over time? To answer this question, consideration needs to be given to the performance of the students in the intervening years to establish a trend which might guide the authors in establishing a reason for this decline.

\subsection{Comparison of students with similar leaving certificate mathematics grades}

In this section, the performance of students in the UL diagnostic test per leaving certificate mathematics grade is outlined and analysed. It was determined that the mean performance 


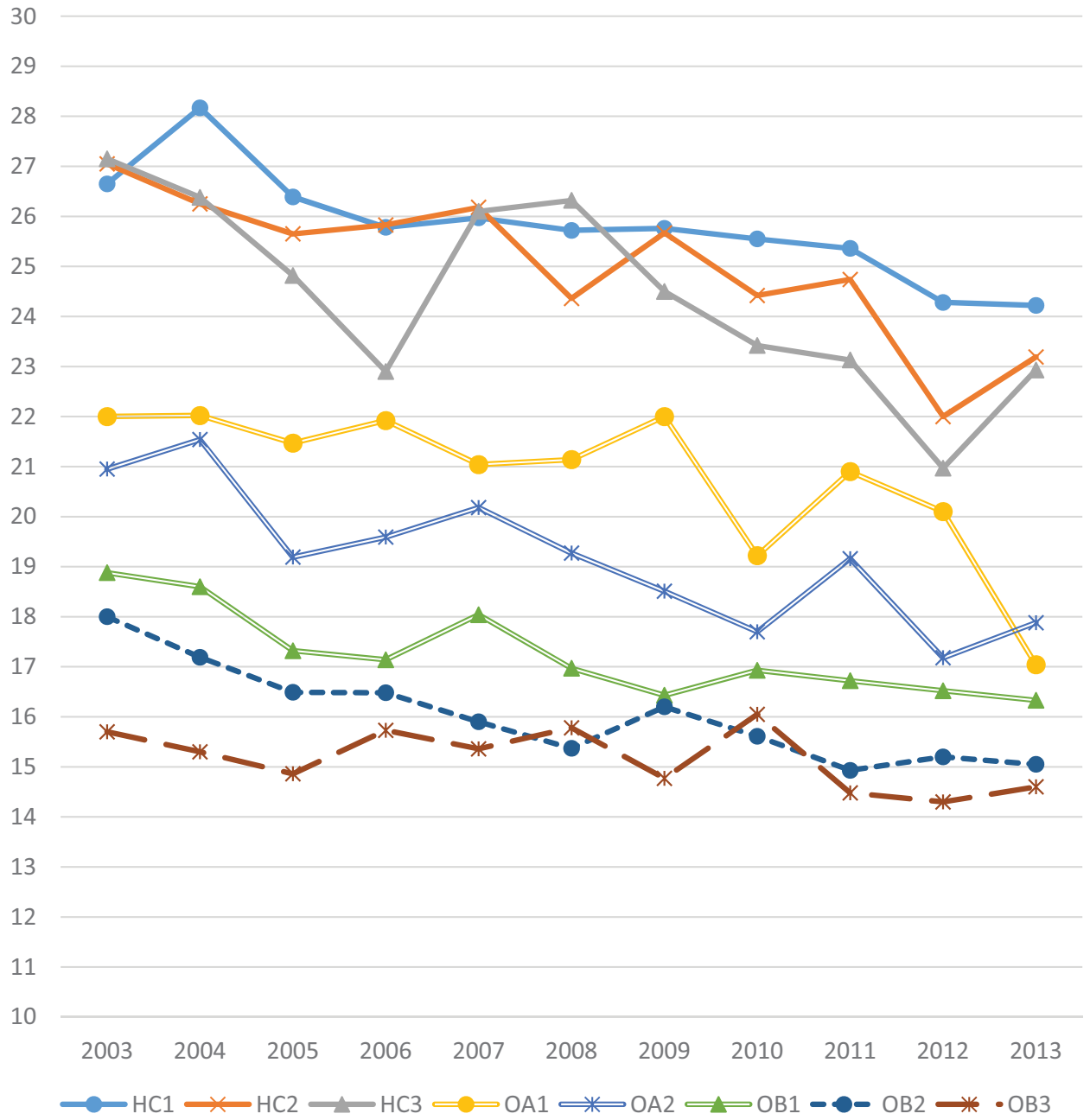

Figure 7. Performance in the diagnostic test of students entering with particular leaving certificate mathematics grades.

in the UL diagnostic test has declined significantly amongst students who have achieved the leaving certificate mathematics grades most commonly found in the UL database (see Figure 7). This is especially true when analysing the performance of students who had previously achieved $\mathrm{C} 2$ and $\mathrm{C} 3$ grades at higher level in the leaving certificate, and A1, A2, and $\mathrm{B} 2$ grades at ordinary level in the leaving certificate.

These findings are surprising, given that Faulkner et al. [19] completed similar analysis of this database for the years 1998-2008 and found no evidence of varying diagnostic test performance per leaving certificate mathematics grade. She concluded that the 'Leaving Certificate Examination is awarding the same grade for a similar average level of mathematical ability as it was ten years ago.' Lawson [3, p.174] carried out a similar investigation with regard to the A level mathematics assessment in the UK, finding that 'in terms of certain basic mathematical skills... A level mathematics does not produce the same degree of competency as it did formerly.' He indicated, for example, that students from 1991 who 
had a grade $\mathrm{N}$ (fail) at A level mathematics performed slightly better than students in 2001 who had achieved a grade B in A level mathematics. The trend of decline reported by Lawson,[3] although not to the same extent, is evident in the UL database utilized in this study.

There is a marked decline in the mean performance of beginning undergraduates in the UL diagnostic test at each of the leaving certificate mathematics grades most common in the UL database (see Figure 7). The difference in mean scores between those recorded in 2003 and those recorded in 2013 are all statistically significant $(p<0.05)$ at each of the leaving certificate mathematics grades highlighted in Figure 7 except for an Ordinary B3 (OB3). The decline in mean scores is most evident when considering students who achieved grades $\mathrm{C} 1, \mathrm{C} 2, \mathrm{C} 3$ at higher level and grades A1 and A2 at ordinary level in leaving certificate mathematics. At these highlighted grades, the decline in mean score on the diagnostic test has fallen by between 2.43 (HC1) and 4.96 (OA1) in the period 2003-2013. As such, students entering service mathematics modules at UL with these leaving certificate grades (higher level C or ordinary level A) are typically answering correctly between two and five questions less in the diagnostic test in 2013 than those who entered UL with the same grade in 2003 .

These declines in performance of basic mathematical skills as outlined above prompt consideration of whether or not grade dilution is currently an issue in leaving certificate mathematics. The marked declines in basic mathematical skills between 2003 and 2013, particularly among students who achieved higher level $\mathrm{C}$ grades and ordinary level A grades in leaving certificate mathematics, would indicate that grade dilution may be a growing concern that needs to be tackled. This can only be definitively determined through further research specific to this issue on a national scale but the indicators present in the data analysed suggest a decline in basic mathematical skills among students transitioning from secondary to tertiary level education even when their leaving certificate mathematics grade is controlled.

A further consideration within this argument of grade dilution is the effectiveness of the UL diagnostic test in assessing basic mathematical skills of students transitioning from secondary level to tertiary level in Ireland over the period 2003-2013. As the leaving certificate mathematics syllabus changed gradually for students sitting the leaving certificate examinations in the years from 2011 onward, this may have affected the suitability of the questions in the diagnostic test.

However, all elements of the diagnostic test continued to be important elements of the 'Project Maths' syllabus, thus, these basic mathematical skills continued to be required for success in mathematics at leaving certificate during the gradual introduction of the new syllabus. Allied to that, the decline in performance of students entering with the most common leaving certificate mathematics grades (see Figure 7) was already evident by 2010 which was before the introduction of the 'Project Maths' syllabus.

The first leaving certificate mathematics examination to be completely based on the new syllabus is due to take place in June 2015 in all Irish secondary schools. With this in mind, the authors recommend that the UL diagnostic test should be reviewed and, if required, adjusted in the near future. This would ensure that the test continues to sufficiently match the Leaving Certificate mathematics syllabus.

\section{Conclusion}

The standard of basic mathematical skills of students entering University of Limerick Science based and Technology based undergraduate courses is in decline. The proportion 
of students deemed to be 'at risk' of failing their service mathematics module in these courses hit its highest mark recorded thus far of 53.7\% in 2012, with a similar proportion of 'at risk' students (48.7\%) recorded in 2013. This is in stark contrast to 2003 and 2004 when this figure was at $30.6 \%$ and $25.6 \%$, respectively. As the number of students entering these modules each year has almost doubled in this time, this indicates that the actual number of students entering UL service mathematics modules who are deemed to be 'at risk' of failing has grown substantially.

The basic mathematical skills of students achieving grades in leaving certificate mathematics examinations most commonly recorded in the UL diagnostic test database is, in recent years, below that of students who achieved the same grades as recently as 10 years previously. Statistically significant declines $(p<0.05)$ in student performance in the UL diagnostic test have been observed at all but one of these grades between 2003 and 2013.

The introduction of the new Project Maths curricula to Irish secondary level mathematics education is only in its initial stages, but these findings would indicate that the transition to these new curricula has coincided with a decline in performance of the basic mathematical skills which are required for students to be fully prepared for service mathematics studied in higher education. It remains to be seen whether the full implementation of the new Project Maths curricula will reverse this decline. In any event, this issue needs to be addressed soon or higher education institutions in Ireland will continue to encounter large numbers of students transitioning from secondary level to tertiary level education without the mathematical skills required to perform to the standards expected.

\section{Disclosure statement}

No potential conflict of interest was reported by the authors.

\section{References}

[1] O'Donoghue J. An Irish Perspective on the "Mathematics Problem", Paper presented at: Irish Symposium for Undergraduate Mathematics Education 2 (ISUME 2). 2nd Annual Meeting; 2004 Dec 10-11; University College Dublin, Ireland.

[2] Gill O, O'Donoghue J, Faulkner F, et al. Trends in performance of science and technology students (1997-2008) in Ireland. Int J Math Educ Sci Technol. 2010;41(3):323-339.

[3] Lawson D. Changes in student entry competencies 1991-2001. Teach Math Applicat. 2003;22(4):171-175.

[4] Rylands L, Coady C. Performance of students with weak mathematics in first-year mathematics and science. Int J Math Educ Sci Technol. 2009;40(6):741-753.

[5] Faulkner F. An analysis of performance in mathematics for technology undergraduates and an investigation of teaching interventions for these students [dissertation]. Limerick: University of Limerick; 2012.

[6] Lawson D, Croft T, Waller D. Mathematics support past, present and future. Innovat Pract Res Eng Educ [Internet]. 2012 [cited 2014 Oct 10]. Available from: http://www.academia.edu/2715773/Mathematics_support_past_present_and_future

[7] McCoy S. Leaving school in Ireland: a longitudinal study of post school transitions. Dublin: ESRI; 2014.

[8] Bourn J. Staying the course: the retention of students in higher education. London: National Audit Office; 2007.

[9] Vorderman C, Porkess R, Budd C, et al. A world-class mathematics education for all our young people [Internet]. 2011 [cited 2014 Oct 10]. Available from: http://www.tsmresources.com/pdf/VordermanMathsReport.pdf

[10] Advisory Committee on Mathematics Education. Mathematical needs: mathematics in the workplace and in higher education. London: The Royal Society; 2011. 
[11] Norris E. Solving the maths problem: international perspectives on mathematics education [Internet]. 2012 [cited 2014 Oct 10]. Available from: http://www.thersa.org/ _data/assets/pdf_file/0011/568181/RSA_Maths_report_10_2_12.pdf

[12] ACT. The condition of college \& career readiness 2014 [Internet]. 2014 [cited 2014 3rd October]. Available from: http://www.act.org/research/policymakers/cccr14/pdf/CCCR14NationalReadinessRpt.pdf

[13] Project Maths Development Team. Overview of project maths [Internet]. 2010 [cited 2014 October 9]. Available from: http://www.projectmaths.ie/overview/.

[14] Ní Ríordáin M, Hannigan A. Out-of-field teaching in post-primary mathematics education: an analysis of the Irish context. Limerick: NCE-MSTL; 2009.

[15] Mooney O, Patterson V, O'Connor M, et al. A study of progression in Irish higher education. Dublin: Higher Education Authority; 2010.

[16] Expert Group on Future Skills Needs. Statement on raising national mathematical achievement. Dublin: EGFSN; 2008.

[17] Jeffes J, Jones E, Wilson M, et al. Research into the impact of Project Maths on student achievement, learning and motivation: final report. Slough: NFER; 2013.

[18] State Examination Commission. State examination statistics [Internet]. Athlone: State Examination Commission; 2003-2014 [cited 2014 Oct 9]. Available from: https://www. examinations.ie/index.php? $1=\mathrm{en} \& \mathrm{mc}=\mathrm{pr} \& \mathrm{sc}=\mathrm{po}$

[19] Faulkner F, Hannigan A, Gill O. Trends in the mathematical competency of university entrants in Ireland by leaving certificate mathematics grade. Teach Math Applicat. 2010;29(2):76-93. 